\title{
O SENSO COMUM EM LIVROS DIDÁTICOS DE SOCIOLOGIA
}

\section{COMMON SENSE IN SOCIOLOGY DIDATIC BOOKS}

\author{
Ricardo Cortez Lopes ${ }^{1}$ \\ ${ }^{1}$ Faculdade IBCMED, Coordenação de Pós-Graduação, Brasil, e-mail: rshicardo@hotmail.com
}

\section{ARTICLE INFO}

Article history:

Received 2020-03-01

Accepted 2020-06-20

Available online 2020-06-20
Palavras-chave: senso comum. Livros didáticos de sociologia. Zeitgeist.

Keywords: common sense. sociology Didatic books. Zeitgeist.

RESUMO. Este artigo analisa a noção de senso comum nos livros didáticos de sociologia brasileira, que normalmente o aplicam na conceituação do que é ciência para delimitar o lugar da sociologia de um ponto de vista epistemológico e pedagógico. Foram analisados livros de sociologia que abordaram o termo "senso comum" e o explicaram, seja de maneira direta ou de maneira indireta. O resultado da pesquisa apontou que a definição indireta se baseia no zeitgeist hegeliano - pois concebe o senso comum como um bloco monolítico de pensamento que se opõe dualmente à ciência - e que a definição direta se baseia na revisão do conceito na filosofia - e o "transplante" dele para o livro didático de sociologia, dado que gera interessantes consequências também para o ensino de filosofia. No fim, refletimos sobre a retirada e a colocada da sociologia e da filosofia nos currículos escolares brasileiras com base no modo como o conceito de senso comum se configurou no corpus empírico analisado, buscando contribuir para e explicação desse fenômeno.

ABSTRACT. This paper analyzes the notion of common sense in Brazilian sociology textbooks, which usually apply it in the conceptualization of what science is to delimit the place of sociology. We analyzed sociology didatic books that addressed the term "common sense" and explained it, either directly or indirectly. The result of the research pointed out that the indirect definition is based on the Hegelian Zeitgeist, and that the direct definition is based on the revision of the concept in philosophy. In the end, we reflect on the withdrawal and placement of sociology and philosophy in Brazilian school curricula based on the way the concept of common sense has been configured.

\section{Introdução}

O conceito de senso comum é uma ferramenta tanto para o ensino de sociologia quanto para o ensino de filosofia. Ele aponta, especificamente, para os saberes prévios dos alunos, aqueles símbolos internalizados que estes "trazem de casa" - ou seja, de sua socialização primária, realizada por sua família até então. Assim, o senso comum acaba se constituindo em uma maneira de colocar em uma ordem de inteligibilidade as diversas manifestações verbais e corporais dos alunos - exceto aquelas que se alinham com as concepções do docente, pois essas já teriam, supostamente, ultrapassado o limiar do consenso da sociedade mais ampla. 
Se essa formulação fosse uma espécie de "segredo" entre os professores, tratar-se-ia de um conceito técnico e operacional e sua problematização não seria assunto complexo fora do ambiente do planejamento. Porém, os professores de sociologia e de filosofia apresentamno também aos seus alunos, o que faz o conceito assumir adicionalmente implicações pedagógicas. Por conta dessa característica, existe a exposição aos alunos em momentos de aula e aquela que é realizada nos livros didáticos. O foco desse texto é na maneira como é realizada a exposição pedagógica desse conceito através de livros didáticos de sociologia.

O que viria a ser um livro didático de sociologia? Não se trata, logicamente, de um texto puro e simples, há outras implicações:

Os livros são, a um só tempo, mercadoria, objeto de política pública, ferramenta de ensino e aprendizagem, artefato intelectual caracterizado por uma modalidade de escrita bastante singular [...] Finalmente não se pode esquecer que o livro didático é elaborado com a finalidade mais imediata de servir de instrumento de ensino e de aprendizagem. Por isso, há uma tensão muito singular do autor de obras didáticas que, afinal, dialoga simultaneamente com o professor e com o aluno (MEUCCl, 2014, p. 214)

Por meio desse conceito, podemos caracterizar o livro didático de sociologia como uma obra polissêmica que busca comunicar com um público amplo e variado ao mesmo tempo em que cumpre com um projeto de aprendizagem do conteúdo programático dessa disciplina. Pesquisar a questão do senso comum é relevante na medida em que evidencia como parte do público discente é concebida pelos escritores desse material pedagógico.

Os livros foram escolhidos para o estudo a partir do critério de haver a expressão literal "senso comum". Por esse filtro foram selecionados seis livros didáticos do universo original, nos quais buscamos definições do conceito através de uma leitura focada. Os resultados foram agrupados entre aqueles que conceituam diretamente o que é senso comum (os quais se relacionam com o conceito de manuais de filosofia), e as formulações indiretas (cujas evidências apontam para uma similaridade com o conceito hegeliano de Zeitgeist). Por fim, realizamos uma discussão sobre as implicações possíveis dessa concepção formulada para a permanência da sociologia e da filosofia no currículo escolar.

\section{Hegel e Zeitgeist}

A filosofia idealista hegeliana é bastante complexa por conta de avançado grau de abstração. Não pretendemos aqui abordar todos os aspectos desse sistema, porque não vamos o utilizar para a análise do material. O que pretendemos operacionalizar é o conceito de Zeitgeist, cuja tradução literal para o português é espírito do tempo. Este é o conceito que 
parece ter sido aplicado pelos formuladores de maneira pontual e, justamente por conta desta pontualidade, optamos por o abordar de maneira mais simplificada, com base em comentadores, sem perder de vista o objeto de estudo:

[...] Hegel tinha por base de sua filosofia o povo - não o indivíduo em sua singularidade - e o contexto em que este povo viveu [...] Da mesma forma, o espírito de uma época é fator determinante para compreender a filosofia hegeliana. $\mathrm{O}$ Zeitgeist é o momento, o contexto em que o espírito está inserido; é uma crítica direta que Hegel faz a todos os sistemas filosóficos anteriores ao seu, que estabeleciam critérios imutáveis para o estudo da filosofia e o que o homem pode conhecer, sem levar em consideração o momento em que isso ocorreria. O Zeitgeist é, em outros termos, o espírito que paira sobre determinada época; é como um espectro que se sustenta em determinado período. Hegel, julgando ser impossível o homem delimitar o conhecimento em verdades eternas, defendia que inexistem verdades que não estejam diretamente vinculadas ao tempo, ao momento, ao contexto histórico de dada época. Ou seja, a filosofia está atrelada à própria história e, assim como esta, é dinâmica, estando em constante movimento, não podendo, portanto, se limitar a uma verdade única e eterna (CONTI, 2018, p.16)

Portanto, o espírito que paira na época, impede que exista de fato um universalismo mecânico para os sistemas filosóficos. Nesse caso, o alemão está colocando bastante peso à variável tempo, que explica a mudança de mentalidades, argumento que corresponde ao seu sistema historicista. Esse espírito é conhecido através da dialética e se expressa por meio desses diferentes Zeitgeist. Porém, cada Zeitgeist não tem noção da existência dos outros, muito menos que eles compõem um Espírito Humano:

Ainda que certamente simplificando, poderíamos resumir do seguinte modo o contexto em que Hegel - para usar a expressão com que lucidamente definiu a tarefa da filosofia - "elevou a conceito o seu tempo": enquanto a burguesia ainda não dominava, houve história, o Espírito atravessou diferentes etapas, valendo-se da ação de "indivíduos histórico-universais" para operar transformações revolucionárias, que destroçaram velhas formas de eticidade e construíram aquelas adequadas à nova figura assumida, em cada etapa concreta, pelo Zeitgeist (COUTINHO, 1997, p.15)

A palavra "etapa" é bem marcante neste trecho, pois são elas que permitem que se perceba que o espírito da época não é nada diante do domínio da burguesia, que começa uma homogeneidade. Ou seja, é preciso conhecer o homem através do espírito da época em que ele viveu:

[...] deve-se observar que a história do mundo está no domínio do Espírito. A palavra "mundo" inclui a natureza física e a natureza psíquica [...] Mas, o Espírito e o rumo do seu desenvolvimento são a matéria da história. [...] Depois da criação da natureza surge o Homem. Ele constitui a antítese ao mundo natural, é o ser que se eleva até o segundo mundo. Temos dois reinos em nossa consciência universal, o reino da Natureza e o reino do Espírito. O reino do Espírito consiste naquilo que é apresentado pelo homem. [...] a essência do Espírito - sua matéria - é a Liberdade. [...] A história do mundo é a exposição do Espírito em luta para chegar ao conhecimento de sua própria natureza. [...] A história do mundo é o avanço da 
consciência da liberdade - um avanço cuja necessidade temos de investigar (HEGEL, 1990, p.61)

Como exploraremos adiante, a busca pela liberdade, do coletivo se dá através da educação desse coletivo. Nas palavras do próprio alemão: "A Razão governa o mundo e, consequentemente, governou sua história. Tudo o mais está subordinado, é subserviente a esta razão universal e material e são os meios para a sua realização [...]" (HEGEL, 1990, p.61). Ou seja, a história é o primeiro vínculo de diferenciação do pensamento entre os homens. Logo, seu conhecimento é condição sine qua nom para a produção da razão.

\section{Senso comum e/ou/contra a ciência: uma revisão do conceito}

A expressão "senso comum" é sinônimo da palavra "consenso" (DICIO, 2019), e etimologicamente é uma inversão do latim consensus, que significa "conformidade de opiniões, sentimentos e impressões" (SIGNIFICADOS, s/d, s/p). O senso comum opera sobre aquilo que é uma concordância em determinado grupo, e o nível de agregação de grupo, nesse caso, pode se expandir desde pequenas associações até sociedades como um todo. Vários livros afirmaram que o contrário de senso comum é o bom senso, a opinião ponderada, como veremos adiante.

Desde a ciência moderna a estratégia epistemológica é desconsiderar os saberes prévios e os preconceitos - basta lembrar de Descartes (1973) se isolando do mundo, em sua casa, para escrever suas meditações metafísicas. Nesse sentido, o senso comum poderia ser equivalente à tradição, daquele conjunto de ideias que são herdadas e que são convincentes por conta da longevidade de seu argumento de autoridade. E é esse senso comum tradicional que desvia do verdadeiro saber, o que exige um "contra-ataque" da ciência moderna: influenciada pelos físicos clássicos Descartes e Newton, ela se auto-define como um conhecimento restrito a quem o alcança pelo domínio da técnica ou, ao menos, dos pressupostos científicos, e por meio dele obter conhecimento sistemático. $O$ outro não saber, o que é oposto, é o da cultura, que é fácil de se adquirir por só exigir a inércia da convivência social, e por isso não é restrito: é o senso comum. Não é impossível cogitar que, em termos platônicos, o senso comum seria o fundo da caverna (PLATÃO, 1987), ou as representações coletivas durkheimianas (DURKHEIM, 1970) que espelham aquilo que é compartilhado no tecido social, ou mesmo a ideologia marxista (MARX, ENGELS, 1974), que é esse ocultamento da realidade para o ocultamento da extorsão material histórica continuada. A ciência durkheimiana deseja as conhecer para poder alcançar uma moralidade adequada à modernidade; Marx, por seu turno, desejava destruir a ideologia por meio de dialética.

Para Durkheim o corte analítico é menos temporal, enquanto que para Marx, um hegeliano, a temporalidade muito explica do senso comum corrente. Dessas concepções se pode 
tirar que se trata de um senso comum como enganação provinda da cultura: "[...] na perspectiva erudita, o senso comum é desqualificado porque banal, destituído de verdade, fonte de equívocos e distorções. E com ele o mundo de que faz parte, o da vida cotidiana" (MARTINS, 1998, p.2). No entanto, a queda das metanarrativas é sinal que o intento moderno se refreia e o grande movimento de intervir conscientemente na realidade também arrefece: é aí que o senso comum passa a ser objeto de estudos, e não só de recusa (MARTINS, 1998). É daí que parte um pluralismo de definições do que é o senso comum. Dessa amplitude, separamos definições no sentido estrito e definições no sentido amplo.

Vamos começar pelas definições estritas, que são mais en passant. Uma das fontes são os manuais de pesquisa social, que são obras próximas dos livros didáticos na sua finalidade:

O senso comum tende a considerar o fato como realidade, isto é, verdadeiro, definitivo, inquestionável e auto-evidente. Da mesma forma, imagina teoria como especulação, ou seja, idéias não comprovadas que, uma vez. submetidas à verificação, se se revelarem verdadeiras, passam a constituir fatos e, até, leis (MARCONI, LAKATOS, 2003, p.114)

O senso comum, para este manual, não exerce a crítica da sua percepção da realidade, e "imagina" que a teoria é mera especulação sem uma base sólida. Em resumo, o conhecimento pontual e não sistematizado marca o senso comum, o que o aproxima da ideia do engano cultural. Citando um outro manual muito importante de pesquisa:

\footnotetext{
- superficial, isto é, conforma-se com a aparência, com aquilo que se pode comprovar simplesmente estando junto das coisas: expressa-se por frases como "porque o vi", "porque o senti", "porque o disseram", "porque todo mundo o diz";

- sensitivo, ou seja, referente a vivências, estados de ânimo e emoções da vida diária;

- subjetivo, pois é o próprio sujeito que organiza suas experiências e conhecimentos, tanto os que adquire por vivência própria quanto os "por ouvi dizer";

- assistemático, pois esta "organização" das experiências não visa a uma sistematização das idéias, nem na fonna de adquiri-las nem na tentativa de validálas;

- acrítico, pois, verdadeiros ou não, a pretensão de que esses conhecimentos o sejam não se manifesta sempre de uma forma crítica (MARCONI, LAKATOS, 2003, p.77)
}

O senso comum, em resumo, acaba se constituindo em uma aproximação individual e precipitada com o mundo do cotidiano, que não constrói uma teoria, um procedimento mais demorado e refletido. É uma coletividade cujos membros concordam entre si por se guiarem aos sentidos, o que permite um consenso que parte do indivíduo. Assim, o senso comum muda porque os indivíduos cambiam, algo que equivale cada contexto a um senso comum; no entanto, não foi relatado um parâmetro espacial nesse cenário, algo que abre brecha para se valorar um parâmetro temporal e histórico.

Outro autor chama o senso comum de conhecimento popular, no sentido de que provém de um "povo", o que remete ao compartilhado: 
O conhecimento popular é valorativo por excelência, pois se fundamenta numa seleção operada com base em estados de ânimo e emoções: como o conhecimento implica uma dualidade de realidades, isto é, de um lado o sujeito cognoscente e, de outro, o objeto conhecido, e este é possuído, de certa forma, pelo cognoscente, os valores do sujeito impregnam o objeto conhecido. É também reflexivo, mas, estando limitado pela - familiaridade com o objeto, não pode ser reduzido a uma formulação geral. A característica de assistemático baseia-se na "organização" particular das experiências próprias do sujeito cognoscente, e não em uma sistematização das idéias, na procura de uma formulação geral que explique os fenômenos observados, aspecto que dificulta a transmissão, de pessoa a pessoa, desse modo de conhecer. É verificável, visto que está limitado ao âmbito da vida diária e diz respeito àquilo que se pode perceber no dia-a-dia. Finalmente é falível e inexato, pois se conforma com a aparência e com o que se ouviu dizer a respeito do objeto. Em outras palavras, não permite a formulação de hipóteses sobre a existência de fenômenos situados além das percepções objetivas (MARCONI, LAKATOS, 2003, P.78)

Nesse sentido, o populi acaba gerando um conhecimento de acordo com seus parâmetros - que não é científico - não sendo sistemático e nem criterioso. Considerando que a ciência possui as características em oposto as do senso comum e que o livro, estabelece-se uma oposição completa entre aquilo que deve ser superado (ou destruído) e aquilo que promove essa destruição. O senso comum e a ciência, respectivamente.

Outras definições estritas apareceram na revisão, provindas de outras áreas. A primeira é de um livro de filosofia: "[...] vasto conjunto de concepções geralmente aceitas como verdadeiras em determinado meio social [...]" (COTRIM, 2002, p.46). Nesse sentido, são concepções construídas coletivamente em um meio social. Outra formulação parte do liberal independentista Thomas Paine, que possuía uma noção de Senso Comum:

A causa da América é, em grande medida, a causa de toda a humanidade. Surgiram, e ainda surgirão, muitas circunstâncias que não são locais, mas universais, através das quais são afetados os princípios de todos os defensores da humanidade, e em cujas ocorrências suas afeições são implicadas. Que se descole um país com Fogo e Espada, declarando guerra aos direitos naturais de toda a Humanidade, extirpando seus defensores da face da Terra, é objeto de atenção de todo Homem a quem a Natureza deu o poder da sensibilidade (PAINE, 2009, p.7)

Para o militante, o senso comum é o direito natural de todo ser humano, o qual os Estados Unidos buscaria solidificar por meio de seu sistema político. Não se trata, propriamente, de uma ideia: ele é uma condição de todo ser humano, não é algo a ser investigado, apenas defendido por meio de argumentação. Não é, portanto, um consenso como é em outras definições, é algo metafísico.

Das definições mais amplas e trabalhadas, vamos começar pela de outro filósofo:

Chamamos senso comum ao conhecimento adquirido por tradição, herdado dos antepassados e ao qual acrescentamos os resultados da experiência vivida na coletividade a que pertencemos. Trata-se de um conjunto de idéias que nos permite 
interpretar a realidade, bem como de um corpo de valores que nos ajuda a avaliar, julgar e portanto agir (ARANHA, 1993, p.51)

Aparece, nestas ideias, a ideia de que há uma tradição e que a experiência vivida que permitem interpretar a realidade e agir nela. Todavia, trata-se de uma construção coletiva baseada em seus próprios termos, nas suas vivências empíricas. Uma coletividade menor, a dos pensadores, produz o chamado bom senso: "Enquanto o senso comum é fragmentário, incoerente, preso a preconceitos e dogmático, o bom senso supõe a capacidade de organização que dá certa autonomia ao homem que analisa sua experiência de vida cotidiana" (ARANHA, 1993,p.87). Nesse caso, o bom senso é o contrário do consenso e nos liberta dele, pois o senso comum conduz ao erro pela sua incoerência e dogmatismo, consequencia de sua construção ser feita por um coletivo não especializado. Mas ainda é possível agregar mais alguns argumentos:

\begin{abstract}
Chamamos de conhecimento espontâneo ou senso comum o saber resultante das experiências levadas a efeito pelo homem ao enfrentar os problemas da existência. Nesse processo ele não se encontra solitário, pois tem o concurso dos contemporâneos, com os quais troca informações. Além disso, cada geração recebe das anteriores a herança fecunda que não só é assimilada como também transformada. O volume enorme de saberes herdados e construídos nem sempre são tematizados, ou seja, não se apresentam de forma sistemática nem têm caráter de conhecimento refletido. Dependendo da cultura, são encontradas, com maior ou menor intensidade, proposições racionais ao lado de crenças e mitos de toda espécie. O senso comum, enquanto conhecimento espontâneo ou vulgar, é ametódico e assistemático e nasce diante da tentativa do homem de resolver os problemas da vida diária. O homem do campo sabe plantar e colher segundo normas que aprendeu com seus pais, usando técnicas herdadas de seu grupo social e que se transformam lentamente em função dos acontecimentos casua is com os quais se depara. É um tipo de conhecimento empírico, porque se baseia na experiência cotidiana e comum das pessoas, distinguindo-se por isso da experiência científica, que exige planejamento rigoroso. É também um conhecimento ingênuo: ingenuidade aqui deve ser entendida como atitude não-crítica, típica do saber que não se coloca como problema e não se questiona enquanto saber [...] Enquanto o senso comum é o conhecimento espontâneo tal como foi descrito, no seu caráter acrítico, difuso, fragmentário, dogmático (ARANHA, 1993, p.138)
\end{abstract}

O senso comum, portanto, é espontâneo na medida em que surge de maneira assistemática para resolver problemas cotidianos - não para entender o porquê dos fenômenos aconteceram. Tal característica o torna naturalmente ingênuo e, por isso, dogmático ao não se questionar sobre seus pressupostos, muitas vezes preconceituosos. Como veremos adiante, muitas dessas ideias retumbaram nas definições diretas de senso comum. Porém, primeiro vamos nos debruçar sobre o conceito indireto.

\title{
4 Conceito Indireto: o zeitgeist
}

Aqui vamos abordar as aplicações do conceito, sem a explicação direta do que seria o senso comum. Nessa percepção aparece uma distinção invisível, entre cotidiano e análise sociológica, como aparece no seguinte trecho: 
A Sociologia nos ajuda a entender melhor essas e outras questões que envolvem nosso cotidiano, sejam elas de caráter pessoal, grupal, ou, ainda, relativas à sociedade à qual pertencemos ou a todas as sociedades. Mas o fundamental da Sociologia é fornecer-nos conceitos e outras ferramentas para analisar as questões sociais e individuais de um modo mais sistemático e consistente, indo além do senso comum (TOMAZI, 2010, p.8)

Nesse caso, o senso comum é uma maneira não-sistemática e não consistente de conceber as questões sociais. É uma oposição clara à sociologia, que possui ferramentas analíticas voltadas exclusivamente para esse fim. Mas podemos perceber que não é só a sociologia que entra na equação, a ciência como um todo também está envolvida:

\begin{abstract}
Estabelecer a diferença entre o seu conhecimento de senso comum com o conhecimento científico; em outras palavras, perceber que os fatos isolados do seu cotidiano (prática) podem ser associados, melhor entendidos e re-elaborados em decorrência de sua relação com a totalidade social (teoria) [...] A problematização de questões do senso comum, presentes em todos nós, deve ser sempre o primeiro momento, o ponto de partida das atividades. Alertamos que essa problematização não deve ser confundida com um simples levantamento dos acontecimentos ocorridos em nossas vidas». Ao contrário, problematizar significa criar uma situação que desperte no aluno a necessidade de entender os fenômenos de seu cotidiano sob outra perspectiva, que não a do senso comum. Em outras palavras, significa mobilizar o aluno para que perceba nos fenômenos sociais particulares uma dimensão geral (teórica) [...] O aluno, por sua vez, também é um organizador e transmissor do conhecimento. Esse conhecimento, porém, muitas vezes apresenta-se desordenado e permeado por noções do senso comum, calcados na experiência cotidiana do aluno. É um conhecimento que não pode ser desprezado, uma vez que consiste na matéria-prima a ser trabalhada pelo professor (MEKSENAS, 1988, p.25)
\end{abstract}

Nesse caso, o senso comum não é completamente refratário, ele é um conhecimento prévio para a sociologia: "desordenado e permeado por noções do senso comum, calcados na experiência cotidiana do aluno". Esse é um conhecimento isolado, que também é conhecimento, mas que é mais massificado. Ou seja, é um segredo compartilhado por poucos iniciados, enquanto o senso comum não o é.

\title{
Outros livros se baseiam em Giddens:
}

Outra categoria significativa em Giddens, quando este autor trabalha com a concepção de ator social e de ação social, é o conceito de consciência prática. A consciência prática se encontra vinculada à prática cotidiana dos atores sociais, que assim não conseguem avaliar as consequências dos próprios atos no agir cotidiano. Afirma Rieth $(2005$, p. 66):

A consciência prática em si mesma não chega a ser uma consciência discursiva. Isto é, normalmente os atores não refletem acerca de suas ações e as problematizam. Não é usual que se distanciem do que fazem e sintam a necessidade de investigar as situações argumentativamente. Isso não implica que inexista neles uma consciência discursiva, que os leve a expressar-se acerca dos contextos sociais, inclusive das condições que determinam seu próprio agir. Estamos diante de determinado "método" de entendimento, integrante dos discursos. Aqui se coloca o pressuposto do denominado senso comum (NERY, 2012, p.65) 
O livro, portanto, utiliza uma espécie de pressuposto, que é "consciência prática", que é aquela que determina o agir. Nesse caso, há uma explicação bem mais detalhada: são pensamentos que não possuem uma reflexividade, o que coaduna com a teoria da estruturação do inglês. Há uma passagem dessa noção para o senso comum, porém o senso comum em si não é uma categoria mobilizada por si.

O senso comum também aparece como prenoção:

Afasta-se assim do senso comum, dos preconceitos e das prenoções e passa a tratar o objeto da sociologia de maneira científica [...] Além de socialização e cultura, outro conceito importante dentro da sociologia é o de instituição social, o qual também sofre algumas "distorções" do senso comum. (PAIXÃO, 2012, p.65)

Assim, existe a equivalência dele com preconceitos. Mas essa distorção não é isolada em uma bolha social: ela também contamina a leitura sociológica. Ou seja, o senso comum precisa ser afastado, não há uma continuidade e ele é potencialmente perigoso para a própria sociologia, o que alinha essas ideias mais com os clássicos.

Outra noção coloca a ideia de separação:

\begin{abstract}
O conhecimento científico é separado do senso comum e de outros saberes, como o religioso, por exemplo. A ciência exige objetividade e universalidade. Talvez seja difícil imaginar como as Ciências Sociais possam ser objetivas e universais, mas foi esse espírito, no final do século XIX, que conduziu a sua formação. As Ciências Sociais se manifestaram inicialmente como o lado científico da análise social: os primeiros cientistas sociais imaginavam poder entender a sociedade do mesmo modo que um físico entendia os fenômenos da gravidade. Hoje já não se imagina que a ciência social seja tão semelhante às ciências exatas ou biológicas. Mas a ideia de que as Ciências Sociais são científicas porque elaboram métodos sistemáticos e testam detalhadamente suas hipóteses ainda é muito importante. Nesse sentido, as Ciências Sociais são distintas da opinião do senso comum [...] Pense na palavra mesa, por exemplo. Aparentemente ela indica um objeto, um móvel de quatro pés cobertos por um tampo, mas, de fato, denota uma ideia. Porém há uma diferença entre os conceitos do senso comum e aqueles produzidos por cientistas sociais. Quando um cientista elabora um conceito, ou se utiliza de um elaborado por outro autor, ele precisa especificar exatamente o que quer dizer com aquele conceito. Em outras palavras, deve evitar as ambiguidades da linguagem e garantir que apenas aquele sentido que conferiu ao conceito será considerado (MACHADO, AMORIM, BARROS, 2013, p.12)
\end{abstract}

A sistematicidade, a testagem de hipóteses e a linguagem ambígua são a definição negativa do senso comum, porém são dadas características, e não uma definição. O conceito científico, portanto, emerge da aplicação desses procedimentos. Porém, não significa que não exista nada de saber fundamentado no senso comum:

\footnotetext{
Mas existe uma lógica em pôr a palha-de-aço na antena. As pessoas só não sabem qual é. E é por esse motivo, também, que Rubem Alves diz que a ciência, na verdade, é um refinamento, ou melhoramento, do senso comum. O senso comum e a ciência nos dão respostas, ou inventam soluções práticas para nossos problemas. A diferença é que a ciência é um conhecimento mais elaborado.[...] A Sociologia é uma das áreas de conhecimento das Ciências Sociais que estuda, de maneira científica, fugindo do senso comum e dos "achismos", a
} 
sociedade [...] Veja, como já falamos, o senso comum não deve ser rejeitado. O que estamos propondo é que você pode ir além desse conhecimento comum, neste caso, sobre a sociedade (LORENSETTI, 2006, p.118)

O senso comum não sabe o motivo de os fenômenos acontecerem - existe um achismo que serve de solução prática, que fecha o problema sem o resolver em outras facetas. Existe uma elaboração no discurso sociológico que o diferencia do conhecimento comum.

No que todas essas formulações indiretas se aproximam do Zeitgeist? Esse pressuposto de que o senso comum é um conhecimento distinto (complementar ou não) do saber dos cientistas - sendo que a gênese dessa distinção é explicada pela falta de sistematicidade remete a um referencial histórico: não há uma explicação com base em diferenças culturais, por exemplo, o que uniformiza o senso comum. Assim, é preciso encontrar uma fonte para a diferenciação social, que nos parece mais estabelecido na dimensão temporal,

Com questão ao papel da história na teoria social, isso varia muito de acordo com o cientista abordado - Levi-Strauss, por exemplo, a colocava entre parênteses, enquanto Marx pensava o materialismo histórico. Esse enfoque na história coaduna com muitas das posições de clássicos da sociologia:

O objeto das ciências sociais é histórico. Isto significa que as sociedades humanas existem num determinado espaço cuja formação social e configuração são específicas. Vivem o presente marcado pelo passado e projetado para o futuro, num embate constante entre o que está dado e o que está sendo construído. Portanto, a provisoriedade, o dinamismo e a especificidade são características fundamentais de qualquer questão social. Por isso, também, as crises têm reflexo tanto no desenvolvimento como na decadência de teorias sociais (MINAYO, 1993, p.13)

Ou seja, a história aqui estabelece uma temporalidade que é independente de qualquer outra explicação. Para este zeitgeist, a sociedade é construída dentro da passagem do tempo: "a provisoriedade, o dinamismo e a especificidade" são marcas desse regime de pensamento que se altera pela variável tempo. Neste caso, a história abarca todas as mudanças, é a variável independente e cerca todas as outras variáveis dependentes. O senso comum trata-se de um construto coletivo socialmente produzido que é preso à sua própria historicidade. Por isso ele acaba sendo não universalista e não reflexivo.

\section{Definições diretas: o rigor na revisão}

As definições diretas tratam de abordagens diretas, onde o senso comum é definido explicitamente e de maneira didática pelos autores. Essa foi uma atitude mais restrita, não foi 
a majoritária entre os atores, apenas dois deles a formularam. O primeiro deles começa por uma ideia de aparência:

Este livro de Sociologia está imbuído desse espírito. Abrir um diálogo com um grande público - os jovens brasileiros do século XXI - e buscar outra visão além do que chamamos de senso comum, ou seja, precisamos compreender e superar as ideias que se baseiam na aparência das coisas, sem uma reflexão mais apurada [...] Um professor de Sociologia define senso comum como: [...] falsas certezas e convicções equivocadas sem a base de um conhecimento racional ou de uma adequada compreensão, sendo ditas pelas pessoas a todo instante sobre as mais diversas coisas. A característica principal é a de que o senso comum baseia-se no que está aparente, na aparência das coisas, como as coisas parecem ser. Por exemplo: o Sol é menor do que a Terra e é ele que gira ao redor dela. Tendo o seu ponto de referência a própria Terra e da maneira que é realizada esta observação, o que pode parecer é que aquela seja uma afirmativa correta. Porém, só parece, pois a Astronomia, com seus cálculos matemáticos e suas considerações físicas verifica na realidade que o Sol é muitas vezes maior que a Terra, e desde Copérnico confirma-se na realidade que é a Terra que se move em torno do Sol. Da mesma forma que este simples exemplo, a Sociologia recorrentemente defronta-se com o senso comum das pessoas, desdobrando-se em imobilidades, discriminações e preconceitos. (GIGLIO, 2000, p. 3)

Ou seja, o foco na aparência por parte de não-cientistas leva a enganos, que resultam em "imobilidades, discriminações e preconceitos", fontes de desigualdades sociais. O senso comum, portanto, origina aspectos muito negativos das relações humanas e a sociologia consegue os reverter por meio de sua disciplina.

Outra definição:

O senso comum se caracteriza por opiniões pessoais, generalizantes. Ou seja, julgam-se coisas ou fatos específicos como se fossem coisas ou fatos universais. Enfim, falsas certezas sem fundamentação científica [...] Ao contrário do investigar as relações entre os fatos e acontecimentos e também suas raízes históricas, como, por exemplo, a questão do racismo na sociedade brasileira (OLIVEIRA, COSTA, 2013, p.18)

Assim, a generalização é procedida sem uma base evidenciada, trata-se de uma premissa que é falseável. Não há uma relação entre os acontecimentos, a mera constatação de sua existência esgota a curiosidade do senso comum. Nesse sentido, fica bem claro que o que foi seguido na formulação do conceito do livro didático aproximou-se muito do referencial da filosofia. Os trechos também mostram que os livros de sociologia acompanham a tendência dos manuais de pesquisa social de não delimitar o que é senso comum sociologia: ele é mais um parâmetro para contrastar o discurso sociológico e mostrar sua relevância social. Mas será que esses dados ajudam a pensar outras questões do ensino de sociologia? 


\section{Uma reflexão final sobre senso comum nos livros didáticos e as idas e vindas da sociologia}

Essa noção de senso comum aponta para a superação de um dualismo, no qual existe uma suplantação da socialização primária por meio da socialização engendrada pelo ensino de sociologia e pelos saberes escolares em geral. O modo como essas noções foram articuladas aponta para "conceitos" ocultos, como o de sociologia militante e o de intelectual orgânico, que constroem também uma imagem a ser compartilhada por quem não é profissional nessa área. O que não implica que os autores dos livros necessariamente sejam marxistas ou gramscinianos, mas sim que seus conceitos possam no mínimo terem sido utilizados pontualmente na sua prática de escrita - algo como o marxismo vulgar descrito por Hobsbawn. Essa conexão parece plausível justamente através do estudo do senso comum expresso por esses livros, pois eles também dão vazão a entender seus autores. Logo, na análise desses livros notamos um sentimento de mobilização contra as desigualdades por meio do saber: um intelectual orgânico romântico, que sonha com um outro mundo e busca o transformar.

Assim, nessa concepção, o que viria a ser um intelectual orgânico?

Consciente da centralidade dos intelectuais no mundo contemporâneo, [Antonio] Gramsci reserva a essa questão um espaço significativo em seus escritos. Ao vivenciar como poucos a nova figura do intelectual militante [...], capta as complexas dinâmicas de expansão da "sociedade civil", que vinha ampliando de forma inédita as expressões intelectuais na "superestrutura" (SEMERARO, 2006, p.376)

Ou seja, o intelectual orgânico é aquele que percebe as dinâmicas reais da estrutura e da superestrutura. Ele pode militar adequadamente na dimensão pública justamente por conhecer essa realidade subjacente, e sua ação é mais efetiva. No contexto do italiano, esse papel estava tão delimitado que a sua concepção acabava sendo otimista. Porém, alguns continuadores intelectuais já não acham que essa atitude é ainda possível na conjuntura atual:

Sofisticado e flexível, nunca o capital se tornou tão abrangente como nessas últimas décadas. Por meio da "indústria cultural", submeteu o conhecimento aos desígnios da produtividade e do mercado, subsumindo, praticamente, toda as esferas da vida social. Difuso por toda parte, parece ter chegado a realizar o seu sonho mais ambicioso: tornar-se poder impessoal, "inconsciente social" [...] máquina que marcha por própria conta, separado do trabalho vivo e do incômodo das revoltas operárias. Sem rosto e sem lugar, o novo soberano hoje se impõe, feito oráculo hermético, pelos indicadores econômicos anunciados todos os dias e por um dilúvio de informações que anulam a reflexão e a interlocução. Longe dos problemas da emancipação humana e imune às investidas da política, essa forma de poder encontra sua lógica mais acabada na cultura pós-moderna, que aprofunda o processo de esvaziamento do concreto pelo abstrato, reduzindo-o à invisibilidade e ao simulacro [...] Nesse contexto, a 
figura do intelectual "engajado" entra em declínio e fala-se cada vez menos de intelectuais "orgânicos", das "classes" trabalhadoras, de "militantes" e de educadores populares (SEMERARO, 2006, p.381)

Nesse caso, o intelectual orgânico estaria "morto" diante do avanço do capital, perdendo a sua função original gramsciniana. Potencialmente, os alunos da escola é que, juntos, podem vir a ser os intelectuais militantes, uma vez que estão sendo acompanhados desde o começo de sua trajetória pela instituição escola: é possível transformar o aluno em um intelectual - que conhece o seu contexto e age nele de maneira consciente e militante.

Por conta desta mudança contextual, no entanto, não é mais o suficiente apenas se estudar a realidade, pois no Brasil existem especificidades na sua estrutura social que agravam o quadro da luta de classes. É preciso, para motivar esse intelectual orgânico, uma "chama" de mudança social, um romantismo:

Essa versão brasileira não se dissociava de traços do romantismo revolucionário da época em escala internacional: a liberação sexual, o desejo de renovação, a fusão entre vida pública e privada, a ânsia de viver o momento, a fruição da vida boêmia, a aposta na ação em detrimento da teoria, os padrões irregulares de trabalho e a relativa pobreza, típicas da juventude de esquerda na época, são características que marcaram os movimentos sociais nos anos 60 em todo o mundo, fazendo lembrar a velha tradição romântica (RIDENTI, 2001, p.13)

Assim, alguns pesquisadores resgatam essa nostalgia, muito marcante nas ciência e cultura dos anos 1960, a partir de uma nova socialização. E, a partir dela, alcançar a mudança do ambiente irradiada pelo grupo de intelectuais:

\begin{abstract}
Entrava em franco declínio o modelo de intelectual ou artista de esquerda dos anos 60, engajado, altruísta, em busca da ligação com o povo tido hoje por muitos como mera expressão do populismo, manipulador dos anseios populares; ou, na melhor das hipóteses, como arquétipo do intelectual quixotesco e ingênuo. Ia-se estabelecendo o protótipo do scholar contemporâneo, egocêntrico, desvinculado de compromissos sociais, a não ser que eles significassem avanço em suas carreiras profissionais individuais, como as dos inúmeros professores que já foram críticos da ordem capitalista a ocupar cargos públicos em governos que adotam medidas neoliberais. Atuam como técnicos a serviço do funcionamento saudável da ordem estabelecida, sem maiores dramas de consciência, talvez se agarrando ainda à ideologia de que estão no poder para o bem do povo e da nação, uma vez amadurecidos e livres das utopias voluntaristas dos anos 60, que só aparentemente teriam sido revolucionárias (RIDENTI, 2001, p.13)
\end{abstract}

Portanto, o Brasil é um ambiente interessante em termos de militância, o que exige maior romantismo do intelectual orgânico: isso porque existe uma profunda desigualdade e uma estrutura social muito rígida. Nesse caso, muitos cientistas acabam assumindo um ethos mais combativo, ligado diariamente aos movimentos sociais:

As aproximações e diferendos entre academia e movimentos sociais têm inspirado elaborações frequentes e apaixonantes. Esse debate, cujo fôlego se agigantou após o surgimento dos designados novos movimentos sociais nas décadas de 1960 e 1970 e 
nomeadamente com os trabalhos de Alain Touraine (1981, 1995, 2002), Alberto Melucci (1995a, 1995b e 1996) e Sidney Tarrow (1994 e 1995), entre outros, conhece renovados contornos à medida que tanto reflexão quanto militância se revestem de um carácter progressivamente complementar, alimentando-se mutuamente no que de particular e comum cada campo apresenta [...] Com efeito, ciência e militância, quando cooperantes horizontais - resistindo vigilantemente à tentação de paternalismo, futurismo ou canibalização, por parte da academia, ou de acomodação, aburguesamento ou cedência, por parte dos movimentos sociais -, podem constituir pedras fundamentais nesse constructo ancorado numa ecologia de saberes e reconhecimentos [...] Na lógica de uma ciência-cidadã, ou seja, aquela cujos saberes resultantes apresentam o potencial de alterar positivamente o mundo ou, pelo menos, os pequenos mundos que afectam as pessoas que constituímos nosso objecto-sujeito de estudo, importa produzir conhecimento que possa constituir-se enquanto instrumento de trabalho para futuras investigações ou outras aplicações académicas, mas também para reflexão interna às associações e planeamento estratégico dos próprios movimentos. De resto, a experiência de investigadores/as-activistas demonstra que a ciência se torna válida na medida em que respeita um compromisso com os princípios de justiça e emancipação. Não creio que tal ameace a objectividade científica; pelo contrário, julgo que tal implicação política obriga a um esforço redobrado de vigilância constante acerca dos possíveis enviesamentos, ao mesmo tempo que se procura atingir porventura a meta principal: aproximar a ciência das pessoas e, obviamente, torná-la mais útil a todos/as.(SANTOS, 2006, p.91)

Neste trecho, podemos observar que existem acadêmicos que consideram possível e desejável a aliança do conhecimento com a práxis dos movimentos sociais, de ativistas: "De resto, a experiência de investigadores/as-activistas demonstra que a ciência se torna válida na medida em que respeita um compromisso com os princípios de justiça e emancipação". Ou seja, a emancipação é essa capacidade de superar o senso comum e suas consequências práticas por meio do ativismo, que desvela as denominações ocultas (e ocultadas) É claro que existem também críticas à essa aliança, pois o ambiente acadêmico não é uniforme:

Desta forma, uma "Sociologia comprometida" (portanto, em alguma medida normativa) pode ser um caminho legítimo na prática das Ciências Sociais, para alguns até inevitável. Uma Sociologia que estaria comprometida pela inevitabilidade de visões de mundo que, necessariamente, os membros deste campo disciplinar compartilham. É radicalmente diferente, contudo, de uma "Sociologia militante", pois esta se orienta, primordialmente, por algum particularismo ideológico e político, o qual antecede e subordina a prática acadêmica, o "fazer cientifico" e rebaixa, ou até elimina, os cânones fundamentais que organizam a produção do conhecimento. Infelizmente, sua existência empobrece em larga medida as Ciências Sociais dedicadas à interpretação do mundo rural brasileiro, pois introduz viseiras ideológicas primárias que limitam as chances de análise criativa e plural. Como enfatiza Martins, "A 'sociologia militante' é a negação absoluta da sociologia como ciência. Sociólogos dessa orientação geralmente usam 'sua sociologia' para impugnar o conhecimento que contraria as conveniências de seu partido político. Ou para dar uma aparência de legitimidade a um conhecimento que foi produzido sem rigor científico" (in Bastos, 2006, p. 141). O caso da reforma agrária no Brasil e sua suposta "necessidade" são paradigmáticos como ilustração: seus defensores intransigentes, nas Ciências Sociais, ainda têm os pés e as mentes nos anos cinqüenta, e não querem perceber que reforma agrária não é mais do que uma política governamental e, como tal, reflete a história do país (NAVARRO, 2008, p.14)

Para este autor, a militância está criando viseiras ideológicas que impedem o comprometimento com a ciência e com a ação social: a produção de conhecimento é particularista e não contribui nem para os pesquisadores e nem para a militância. $O$ objeto 
pode ser o mesmo, mas a sociologia comprometida é mais voltada para os procedimentos científicos. Para essa sociologia, superar o senso comum (que não é sistemático e ainda é particularista) habilita o cidadão a participar ativamente da deliberação, o que dá espaço também para o ativismo:

\begin{abstract}
Hoje, boa parte da esquerda recorda-se com saudades dos anos dourados do otimismo socialdemocrático. Segundo essa visão, os anos 1950 e 1960 aparecem como uma época de crescente prosperidade e harmonia social, com o "Welfare State Keynesiano" realizando a visão socialdemocrática de uma sociedade que combina o dinamismo econômico do capitalismo com os valores políticos do socialismo. Em conseqüência, a "crise da social democracia" não é vista como um fracasso dessa concepção, mas apenas da sua concretização - fracasso criado por mudanças econômicas fundamentais que tornaram um socialismo monolítico e burocrático inadequado para os novos modos de organização. Ao compreender que as crescentes crises econômicas, sociais e ambientais mostram que o modelo neoliberal de desregulação não oferece uma solução viável, a social-democracia vem se empenhando em construir um novo modelo de regulação a fim de concretizar a velha idéia (CLARKE, 1991, p.118).
\end{abstract}

Porém, além do conhecimento espontâneo da sociedade, há ainda uma colocação em xeque do conhecimento da própria escola, pois o capitalismo estaria penetrando todas as esferas da vivência humana - o que afeta o próprio intelectual orgânico, como vimos. Nesse caso, a sociologia e a filosofia dos professores que seguem esse marco teórico trazem o romantismo e o engajamento na busca de uma outra sociedade que não a já estabelecida, desigual e injusta. Porém, a democracia representativa precisa de um sedimento mais sólido e de cidadãos mais engajados - e o discurso que nega a socialização pode criar o efeito de mobilização para um perfil de alunos e de desmotivação para outro tipo de aluno.

Assim, o foco dos ensinos de filosofia e de sociologia ser a ação no mundo da vida é uma noção habermasiana, da escola de Frankfurt. No projeto da modernidade primeira, isso fazia total sentido para criar uma realidade contraposta à tradição, pois era preciso criar a mentalidade moderna a partir da pedagogia moderna. $O$ ensino das ciências passou a pretender ajudar a povoar os imaginários com a cultura modernizada, o que inclui as ciências que são mais fixas no currículo escolar brasileiro: geografia, química, biologia, história, etc.

Talvez seja aí é que resida a dificuldade da filosofia e da sociologia em permanecer na grade: os ensinos de filosofia e sociologia desejam mais do que aprofundar o saber prévio do senso comum, pretendem ressignificar a experiência com o mundo da vida. Isso é, portanto, diferente qualitativamente da abordagem das outras disciplinas, que no máximo querem derrubar mitos pontuais de sua área. Agir no senso comum é sistêmico: seria uma dessocialização, algo que poderia ser mais útil na modernidade primeira do que na modernidade mais consolidada. Porém, quando se afirma que a escola pode também socializar erroneamente, a modernidade inteira passa a ser contestada. E nesse caso colegas da área da educação podem se opor a essas disciplinas no espaço escolar. Assim, não se trata apenas de um conflito com o estado, filosofia e sociologia, devido à sua discussão com o senso comum, podem conflitar inclusive com outras áreas do conhecimento. 


\section{Considerações Finais}

Este artigo procurou estudar o conceito de senso comum em livros didáticos de sociologia para o ensino médio brasileiro. O estudo apontou duas definições de senso comum, uma indireta (ligada ao zeitgeist hegeliano) e outra direta (ligada à filosofia). Assim, uma das conclusões possíveis é a de que se trata de um conceito pouco explicado, mas que remete a um discurso unificado. Em procedimento ele se forma como o referencial teórico filosófico; na prática, mediante a profusão de exemplos da temporalidade, aponta-se para uma acentuada importância para a historicidade, forte evidência do historicismo hegeliano.

O assunto do senso comum é presente tanto no ensino de sociologia e no ensino de filosofia. Mas essa não é a única característica em comum: ambas também saem e retornam para o currículo escolar, o que se caracteriza uma certa instabilidade em sua oferta ao longo dos anos. Outra característica é a sua busca por problematizar a socialização primária, o que é diferente de outras disciplinas do currículo da escola básica, cujo mote é expandir os saberes cotidianos sem os contestar diretamente - talvez aperfeiçoar seja a palavra mais adequada.

Como Hegel pode ter sido referência para esses escritores? Provavelmente através da obra de Marx, um hegeliano de esquerda e cuja dialética é bem marcante na história intelectual brasileira - basta, por exemplo, analisar a obra do sociólogo Florestan Fernandes, marxista que ajudou a consolidar a disciplina como ciência no país. Porém, o cientista social brasileiro ainda é bem rigoroso na questão conceitual, o que é demonstrado nas semelhanças com o conceito de senso comum dos livros didáticos com os livros de filosofia.

Concluímos esse texto afirmando que há um perigo de dogmatismo nessa discussão dualista senso comum-ciência. Isso porque, por mais que haja rigor e verificação entre pares, é justamente essa deliberação que causa o pluralismo entre os profissionais da pesquisa: "O campo científico, apesar de sua normatividade, é permeado por conflitos e contradições" (MINAYO, 1993, p.10). Afirmar que o campo científico e o campo do senso comum são uniformes é um preconceito que pode prejudicar a comunicação entre pesquisadores e a sociedade. Algo que pode ter implicações na legitimidade da própria ciência como um todo. 


\section{Referências}

ARANHA, Maria Lúcia de Arruda. Filosofando. São Paulo: Moderna, 1993.

CLARKE, Simon. Crise do Fordismo ou Crise da Social-Democracia? Lua nova, v.1, n.24, p.117-150, 1991.

CONTI, Thiago Fernando Spanholeto. Uma análise do movimento Zeitgeist: liberalismo e utilitarismo. 2018. 1 recurso online (107 p.). Dissertação (mestrado) Universidade Estadual de Campinas, Faculdade de Ciências Aplicadas, Limeira, SP. COUTINHO, Carlos Nelson. ' In: Conferência apresentada no Instituto de Estudos Avançados da Universidade de São Paulo.. 1997.

COTRIM. Gilberto. Fundamentos da filosofia: história e grandes temas. 15. ed. São Paulo: Saraiva, 2002.

DESCARTES, René. Discurso do método: Meditações: Objeções e respostas: As paixões da alma; Cartas. Rio de Janeiro: Abril Cultural, 1973.

DICIO. Significado de Senso comum. Dicionário Online de Português. 2019. Disponível em: https://www.dicio.com.br/senso-comum/. Acesso em 23/08/2019.

DURKHEIM, É. Sociologia e filosofia. São Paulo, Ed. Forense, 1970.

HEGEL, G. W. F. A razão na História. Uma introdução geral à Filosofia da História. São Paulo: Editora Moraes, 1990.

LORENSETTI, Everaldo. O surgimento da sociologia. In: VÁRIOS. Sociologia. Curitiba: SEED-PR, 2006.

MACHADO, Igor José de Renó; AMORIM, Henrique; BARROS, Celso Rocha de. Sociologia hoje: volume único : ensino médio. 1. ed. São Paulo : Ática, 2013.

MARCONI, Marina de Andrade; LAKATOS, Eva Maria. Fundamentos de metodologia científica. São Paulo: Atlas, 2003.

MARTINS, José de Souza. O senso comum e a vida cotidiana. Tempo social, v. 10, n. 1, p. 1-8, 1998.

MARX, Karl e ENGELS, F. A ideologia alemã. São Paulo, Martins Fontes, 1974.

MEKSENAS, Paulo. Sociologia Geral. São Paulo: Cortez, 1988. 
MEUCCI, Simone. Notas sobre o pensamento social brasileiro nos livros didáticos de sociologia. Revista brasileira de sociologia, Vol 02, No. 03, Jan/Jun/2014, p.207232

MINAYO, Maria Cecília de Souza. Pesquisa Social: teoria, método e criatividade. Petrópolis: Vozes, 1993.

NAVARRO, Zander. " Nunca cruzaremos este rio"-a estranha associação entre o poder do atraso, a história lenta e a" sociologia militante", e o ocaso da reforma agrária no Brasil. Redes, Santa Cruz do Sul, v. 13, n. 2, p. 5-51, 2008.

NERY, Maria Clara Ramos. Sociologia contemporânea. 1.ed. rev. Curitiba: IESDE Brasil, 2012.

OLIVEIRA, Luiz Fernandes de, COSTA, Ricardo Cesar Rocha da. Sociologia para jovens do século XXI. 3.ed. Rio de Janeiro: Imperial Novo Milênio, 2013.

PAINE, Thomas. O senso comum. Porto Alegre: L\&PM, 2009.

PLATÃO. A República. Lisboa: Fundação Calouste Gulbenkian; 1987.

PAIXÃO, Paixão, Alessandro Eziquiel da. Sociologia geral. Curitiba: Ibpex, 2012.

RIDENTI, Marcelo. Intelectuais e romantismo revolucionário. São Paulo em perspectiva, v. 15, n. 2, p. 13-19, 2001.

SANTOS, Ana Cristina. Entre a academia e o activismo: Sociologia, estudos queer e movimento LGBT em Portugal. Revista Crítica de Ciências Sociais, n. 76, p. 91-108, 2006.

SEMERARO, Giovanni. Intelectuais "orgânicos" em tempos de pós-modernidade. Caderno Cedes, Campinas, vol. 26, n. 70, p. 373-391, set./dez. 2006

SIGNIFICADOS. Significado de Consenso. Significados Br. Sem Data. Disponível em: https://www.significadosbr.com.br/consenso. Acesso em: 23/08/2019.

TOMAZI, Nelson Dacio. Sociologia para o ensino médio. 2. ed. São Paulo: Saraiva, 2010. 